\title{
Histopathological Assessment of Liver Biopsy Specimen in the Context of HBV DNA and HBeAg in Patients with Chronic Hepatitis B
}

\author{
${ }^{1}$ Naznin Nahar, ${ }^{2}$ Mamun-AI-Mahtab, ${ }^{3}$ AJE Nahar Rahman, ${ }^{4}$ Sheikh Mohammad Fazle Akbar, ${ }^{3}$ Saequa Habib \\ ${ }^{1}$ Department of Pathology, Dhaka Community Medical College, Dhaka, Bangladesh \\ ${ }^{2}$ Department of Hepatology, Bangabandhu Sheikh Mujib Medical University, Dhaka, Bangladesh \\ ${ }^{3}$ Department of Pathology, Bangabandhu Sheikh Mujib Medical University, Dhaka, Bangladesh \\ ${ }^{4}$ Department of Medical Sciences, Toshiba General Hospital, Tokyo, Japan
}

Correspondence: Mamun-Al-Mahtab, Assistant Professor, Department of Hepatology, Bangabandhu Sheikh Mujib Medical University, Shahbagh, Dhaka-1000, Bangladesh, e-mail: shwapnil@agni.com

\begin{abstract}
Background: There is lack of consensus if hepatitis B virus (HBV) DNA can be regarded as a surrogate marker of liver damages in patients with chronic hepatitis B (CHB).

Methods: A total of 77 patients with CHB were enrolled in this study. The sera of the patients were tested for HBV DNA and hepatitis B e antigen (HBeAg). The extent of hepatitis and hepatic fibrosis was assessed by liver biopsy.

Results: Out of total of 77 patients with $\mathrm{CHB}, 29$ were HBeAg-positive and 48 were HBeAg-negative. Twenty-seven of $29 \mathrm{HBeAg}$-positive patients and eight of $48 \mathrm{HBeAg}$-negative patients had high levels of HBV DNA (HBV DNA $>10^{5} \mathrm{copies} / \mathrm{ml}$ ). The extent of hepatitis was minimal or mild in most HBeAg-positive CHB patients (27 of 29) irrespective of the levels of HBV DNA in the sera. Moderate levels of hepatitis were seen in two HBeAg-positive patients and five HBeAg-negative patients. Moderate levels of hepatic fibrosis were seen in four of eight HBeAg-negative patients with high HBV DNA.

Conclusion: This study shows that HBV DNA and HBeAg do not reflect the extent of hepatitis or hepatic fibrosis in CHB patients of Bangladesh. Combination of different HBV-related markers with liver biopsy is required for proper diagnosis and management of $\mathrm{CHB}$ in Bangladesh.

Abbreviations: HBV: Hepatitis B virus; HBsAg: Hepatitis B surface antigen; HBeAg: Hepatitis B e antigen; ALT: Alanine aminotransferase; CHB: Chronic hepatitis B; HAl: Histology activity index.

Keywords: HBV DNA, HBeAg, Hepatitis, Hepatic fibrosis, Bangladesh.
\end{abstract}

\section{INTRODUCTION}

HBV, a member of the family Hepadnaviridae, is a noncytopathic DNA virus. About 2 billion people have been infected globally at some point in their lives with HBV, and approximately 350 to 400 million people are chronically infected with this virus. Epidemiologic data indicate that HBV accounts for 0.5 to 1.2 million deaths annually, and approximately 15 to $25 \%$ of chronic hepatitis B patients will eventually die of HBV-related liver disease. ${ }^{1,2}$

Chronic HBV-infected subjects express different virological, biochemical, immunological and histological markers; some of which are detectable in the sera; whereas, others can be assessed in liver biopsy specimens. HBV DNA, HBsAg, HBeAg and ALT are detected in the sera for diagnosis of HBV infection and to assess extent of liver damages in patients with CHB. However, liver biopsy provides most critical evidences of liver injury. It is a matter of controversy whether HBV DNA may be used as surrogate marker of liver damages in CHB patients. Some investigators have shown that HBV DNA levels may be useful in this context. ${ }^{3-8}$ However, data contrary to this conception also exist and it seems that serum HBV DNA may not reflect the extent of liver damages in CHB patients. ${ }^{9-12}$

Bangladesh, a South Asian country with 160 million people, exhibits an intermediate prevalence for HBV infection. The lifetime risk of acquiring this infection in Bangladesh is $>40 \%$. It has been shown that this virus is responsible for about 10 to $35 \%$ cases of acute viral hepatitis, about $35 \%$ cases of fulminant hepatic failure, about 33 to $40 \%$ cases of chronic hepatitis and $46 \%$ cases of hepatocellular carcinoma. ${ }^{13}$

The apparent discrepancies about usefulness of HBV DNA in determining extent of liver damages may be due to 
differences of study population and other explored factors. However, this has tremendously comprised both proper diagnosis and effective management of $\mathrm{CHB}$ patients in most developing countries. This present study in which HBV DNA and HBeAg were compared with findings of liver biopsy in 77 consecutive patients with CHB in Bangladesh provided information about complexity of $\mathrm{HBV}$ management at Bangladesh.

\section{MATERIALS AND METHODS}

Patients with chronic HBV infection (HBsAg-positive for at least 6 months) attending Department of Hepatology, Bangabandhu Sheikh Mujib Medical University, Dhaka, Bangladesh between March 2008 and December 2008 were enrolled in this study. Written informed consent was obtained from each patient. The patients were positive for serum HBV DNA and negative for antihepatitis $C$ virus antibody.

Serum ALT levels and prothrombin time were assessed commercially. The cutoff value for abnormal ALT was 42 U/L. HBeAg was checked commercially by ELISA using a commercial kit (Abbott Labs, Chicago, IL, USA). Serum HBV DNA was quantified in a polymerase chain reaction method using a commercial kit (Amplicon HBV Monitor Assay, RT-PCR, Roche Molecular Systems, CA, USA). The lower limit of detection was 500 copies of HBV DNA/ml.

A percutaneous liver biopsy was performed with written consent of the patients. Biopsies were performed under local anesthesia using a 16G Tru-cut biopsy needle (Cardinal Health, McGaw Park, IL, USA). A biopsy specimen of more than $1.0 \mathrm{~cm}$ in length with five to six portal tracts was accepted when examined microscopically. Histology was graded according to the histologic activity index (HAI) using the criteria of Knodell et al. ${ }^{14}$ The total HAI score comprises necroinflammation (HAI-N1) and fibrosis (HAI-F) scores. The HAI-N1 scale includes three components (0-10, piecemeal necrosis; 0-4, lobular necrosis and inflammation; $0-4$, portal inflammation). Minimal hepatitis, mild hepatitis, and moderate hepatitis were regarded when HAI-N1 score was 0-4, 5-8 and 9-12 respectively. HAI-F was graded according to severity: 0 , absence of fibrosis; 1 , fibrous portal expansion; 3 , bridging fibrosis; 4 , cirrhosis.

\section{RESULTS}

A total of 77 patients were enrolled in the study to assess the relationship of HBV DNA and HBeAg with extent of liver damages or hepatitis. HBV DNA and HBeAg were assessed in the sera and extent of hepatitis was evaluated by liver biopsy. On the basis of levels of HBV DNA in the sera, the patients were divided in two groups: (1) high HBV
DNA; patients expressing HBV DNA of $>10^{5}$ copies $/ \mathrm{ml}$, and (2) low HBV DNA; patients with HBV DNA of $<10^{5}$ copies/ml in the sera.

Twenty-nine out of 77 patients were HBeAg-positive and the rest 48 were HBeAg-negative. Out of $29 \mathrm{HBeAg-}$ positive patients, 27 (93\%) had high levels of HBV DNA, whereas only 2 (7\%) had low levels of HBV DNA in the sera. However, levels of HBV DNA showed a different picture in HBeAg-negative patients. Out of $48 \mathrm{HBeAg}-$ negative patients, HBV DNA levels were $>10^{5}$ copies $/ \mathrm{ml}$ in 8 patients, whereas the rest 40 patients of this group had low HBV DNA. Taken together, 35 patients had high HBV DNA, whereas 42 patients had low HBV DNA in the sera in this cohort.

The main purpose of this study was to assess if there is a relation between serum HBV DNA or HBeAg with extent of hepatitis or hepatic fibrosis in liver biopsy. As described in the Method section, the extent of hepatic inflammation and liver fibrosis was graded according to the criteria of Knodell et al. When the necrosis score was HAI-N1 0-4, the patients were regarded to have minimal hepatitis. On the contrary, if the levels of hepatic inflammation were HAIN1 5-8 and HAI-N1 9-12, they were regarded as having mild and moderate hepatitis, respectively. A total of 36, 34 and seven patients had minimal, mild and moderate hepatitis (Table 1).

Next, we assessed if the levels of HBV DNA reflect the levels of liver injury in CHB patients. As shown in Table 2, out of 35 patients with high HBV DNA, only 5 had moderate levels of hepatitis. The levels of hepatitis were minimal or mild in rest 30 patients with high levels of HBV DNA. Moderate levels of hepatitis were detected in two out of 42 patients with low HBV DNA.

The relation between HBeAg expression and extent of hepatitis has been shown in Table 3. Mild hepatitis was equally distributed between HBeAg-positive and HBeAgnegative patients in this cohort. Moderate hepatitis was seen in higher ratio in HBeAg-negative patients (5 of 48, 10.4\%) than in HBeAg-positive patients (2 of 29, 6.9\%).

\begin{tabular}{|c|c|c|}
\hline Extent of hepatitis & $\begin{array}{c}\text { Number of } \\
\text { patients }\end{array}$ & Percentage \\
\hline Minimal hepatitis (HAI N1 0-4) & 36 & $47 \%$ \\
\hline Mild hepatitis (HAI N1 5-8) & 34 & $44 \%$ \\
\hline Moderate hepatitis (HAI N1 9-12) & 7 & $9 \%$ \\
\hline Total & 77 & $100 \%$ \\
\hline
\end{tabular}

Note: All patients had a liver biopsy and the levels of inflammation were assessed, according to Knodell et al. 
Table 2: Extent of hepatitis and levels of HBV DNA in patients with chronic hepatitis B

\begin{tabular}{|c|c|c|c|c|c|c|}
\hline \multirow{2}{*}{$\begin{array}{l}\text { HBV DNA level } \\
\text { (copies/ml) }\end{array}$} & \multicolumn{2}{|c|}{ Minimal hepatitis } & \multicolumn{2}{|c|}{ Mild hepatitis } & \multicolumn{2}{|c|}{ Moderate hepatitis } \\
\hline & No. & $\%$ & No. & $\%$ & No. & $\%$ \\
\hline $\operatorname{High}\left(>10^{5}\right)$ & 11 & 31 & 19 & 56 & 5 & 71.42 \\
\hline Low $\left(<10^{5}\right)$ & 25 & 69 & 15 & 44 & 2 & 28.57 \\
\hline Total & 36 & 100 & 34 & 100 & 7 & 100 \\
\hline
\end{tabular}

Table 3: Serum HBeAg and extent of hepatitis in patients with chronic hepatitis B

\begin{tabular}{|c|c|c|c|c|c|c|}
\hline \multirow[t]{2}{*}{ Serum HBeAg status } & \multicolumn{2}{|c|}{ Minimal hepatitis } & \multicolumn{2}{|c|}{ Mild hepatitis } & \multicolumn{2}{|c|}{ Moderate hepatitis } \\
\hline & No. & $\%$ & No. & $\%$ & No. & $\%$ \\
\hline Positive & 10 & 28 & 17 & 50 & 2 & 29 \\
\hline Negative & 26 & 72 & 17 & 50 & 5 & 71 \\
\hline Total & 36 & 100 & 34 & 100 & 7 & 100 \\
\hline
\end{tabular}

The extents of hepatic fibrosis were mild in most HBeAgpositive patients with CHB irrespective of their HBV DNA levels. In 24 of $27 \mathrm{HBeAg}$-positive patients with high HBV DNA, had minimal to mild fibrosis (HAI-F 0-1). Also, two HBeAg-positive patients with low HBV DNA have minimal to mild fibrosis (HAI-F 0-1). However, in HBeAg-negative patients, four of eight patients with high HBV DNA had bridging fibrosis (HAI-F 3) and the rest four patients had mild hepatic fibrosis. In HBeAg-negative patients with low HBV

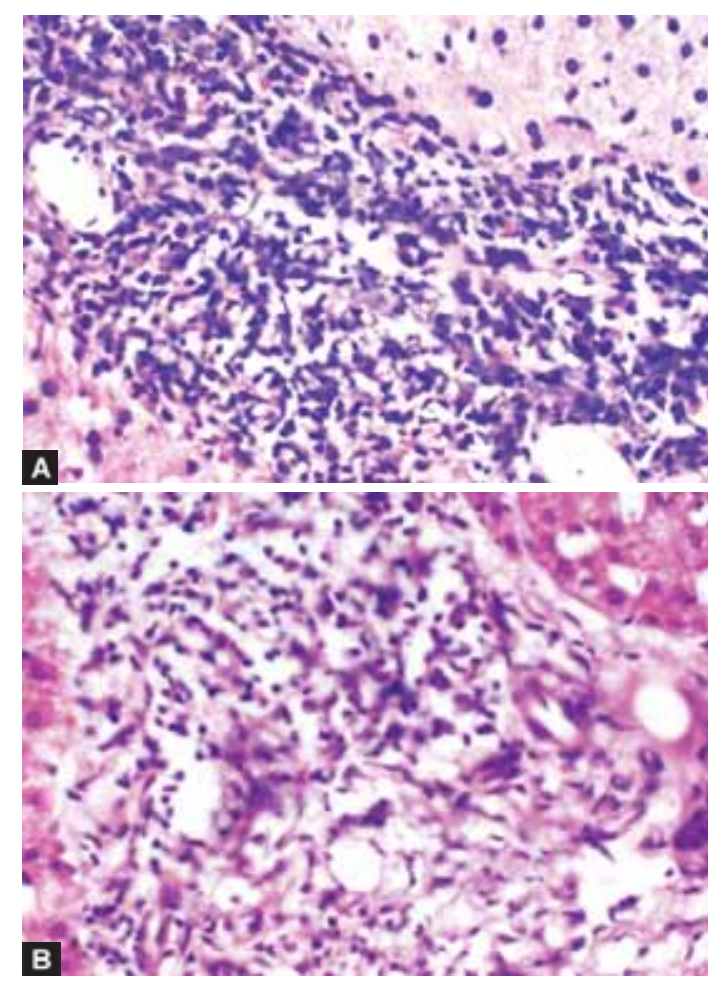

Figs 1A and B: (A) Moderate levels of hepatitis in liver biopsy specimen in $\mathrm{HBeAg}$-positive patient with chronic hepatitis $\mathrm{B}$. The patient was a 28-year-old female. The level of alanine aminotransferase (ALT) was $27 \mathrm{U} / \mathrm{L}$. The HBV DNA was $4.7 \times 10^{11} \mathrm{copies} / \mathrm{ml}$. (B) Moderate level of hepatitis with interface hepatitis in $\mathrm{HBeAg}$-positive patients with $\mathrm{CHB}$. The patient was 19-year-old female with ALT of $28 \mathrm{U} / \mathrm{L}$ and HBV DNA was $4.8 \times 10^{5}$ copies $/ \mathrm{ml}$
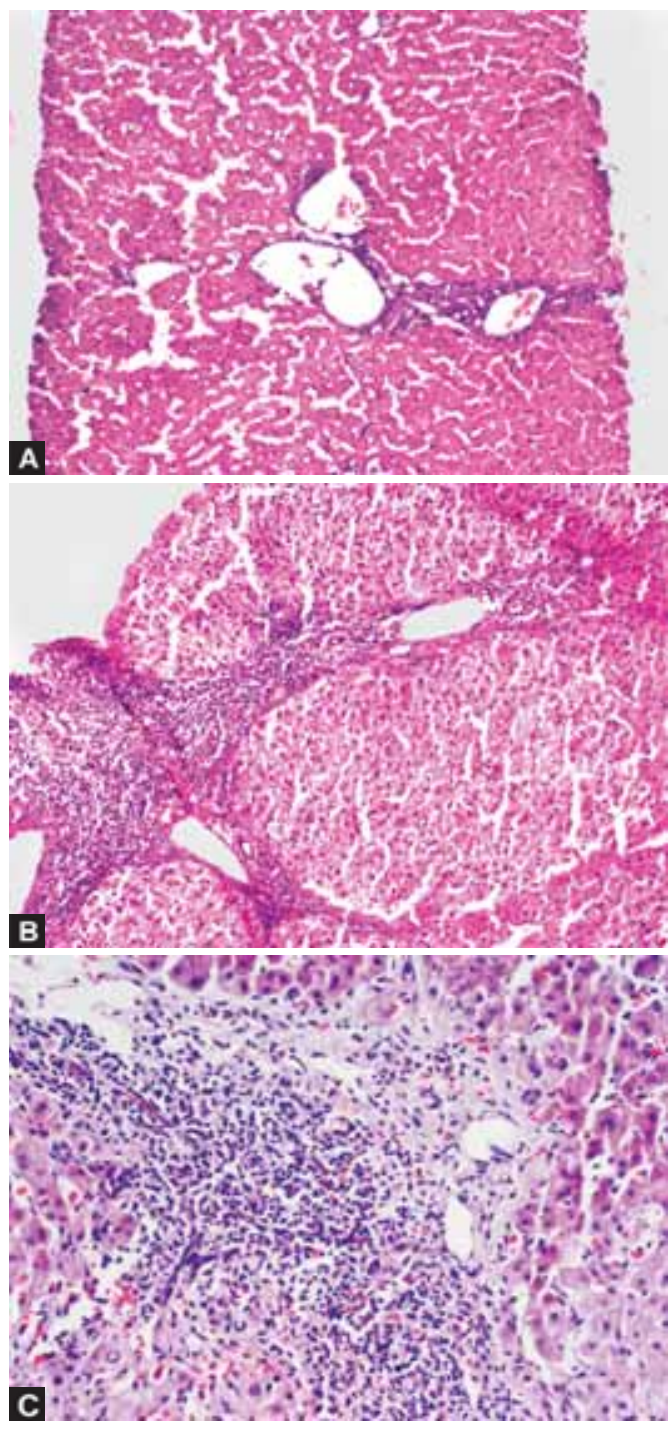

Figs 2A to C: (A) Mild portal inflammation and mild piecemeal necrosis in $\mathrm{HBeAg}$-negative $\mathrm{CHB}$ patient. The level of ALT was $30 \mathrm{U} / \mathrm{L}$ and HBV DNA was $1.1 \times 10^{4}$ copies $/ \mathrm{ml}$. (B) Moderate piecemeal necrosis with bridging necrosis and bridging fibrosis in $\mathrm{HBeAg}$-negative $\mathrm{CHB}$ patient. The level of ALT was $36 \mathrm{U} / \mathrm{L}$ and HBV DNA was $1.88 \times 10^{5}$ copies $/ \mathrm{ml}$. (C) Moderate piecemeal necrosis with bridging necrosis and bridging fibrosis in a patient with HBeAg-negative CHB with ALT of $36 \mathrm{U} / \mathrm{L}$ and HBV DNA of $1.3 \times 10^{5}$ copies $/ \mathrm{ml}$ 
Table 4: Biochemical, serological and histological parameters of patients with chronic hepatitis B

Case Age Sex Biochemical Serological Histology active index

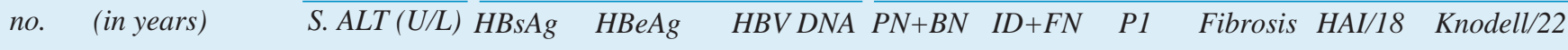
copies $/ \mathrm{ml}$

\begin{tabular}{|c|c|c|c|c|c|c|c|c|c|c|c|c|}
\hline 1. & 12 & $\mathrm{~F}$ & 20 & +ve & -ve & $4.1 \times 10^{3}$ & 1 & 1 & 1 & 1 & 3 & 4 \\
\hline 2. & 39 & $\mathrm{M}$ & 80 & +ve & -ve & $2 \times 10^{3}$ & 1 & 1 & 3 & 1 & 5 & 6 \\
\hline 3. & 20 & M & 46 & +ve & -ve & $6.7 \times 10^{3}$ & 1 & 1 & 1 & 1 & 3 & 4 \\
\hline 4. & 28 & M & 65 & $+\mathrm{ve}$ & -ve & $1.1 \times 10^{3}$ & 1 & 1 & 1 & 1 & 3 & 4 \\
\hline 5. & 40 & M & 33 & + ve & -ve & $9.6 \times 10^{3}$ & 1 & 1 & 1 & 1 & 3 & 4 \\
\hline 6. & 28 & M & 84 & +ve & -ve & $9 \times 10^{3}$ & 3 & 1 & 3 & 3 & 7 & 10 \\
\hline 7. & 22 & $\mathrm{~F}$ & 24 & +ve & -ve & $2.4 \times 10^{3}$ & 1 & 1 & 1 & 3 & 3 & 6 \\
\hline 8. & 20 & M & 32 & +ve & -ve & $7.7 \times 10^{3}$ & 1 & 1 & 1 & 1 & 3 & 4 \\
\hline 9. & 52 & M & 30 & +ve & -ve & $1.4 \times 10^{3}$ & 1 & 1 & 1 & 1 & 3 & 4 \\
\hline 10. & 34 & M & 60 & +ve & -ve & $1.6 \times 10^{3}$ & 3 & 1 & 3 & 1 & 7 & 8 \\
\hline 11. & 28 & M & 35 & +ve & -ve & $1.6 \times 10^{3}$ & 1 & 1 & 1 & 1 & 3 & 4 \\
\hline 12. & 26 & M & 54 & +ve & -ve & $6.2 \times 10^{3}$ & 1 & 1 & 1 & 1 & 3 & 4 \\
\hline 13. & 27 & M & 85 & +ve & -ve & $9.2 \times 10^{3}$ & 3 & 1 & 3 & 1 & 7 & 8 \\
\hline 14. & 36 & M & 38 & +ve & -ve & $2.9 \times 10^{3}$ & 1 & 1 & 1 & 1 & 3 & 4 \\
\hline 15. & 31 & M & 30 & +ve & -ve & $2.5 \times 10^{4}$ & 3 & 1 & 3 & 3 & 7 & 10 \\
\hline 16. & 19 & M & 54 & + ve & +ve & $5.5 \times 10^{11}$ & 3 & 1 & 3 & 3 & 7 & 10 \\
\hline 17. & 23 & M & 42 & +ve & +ve & $8.6 \times 10^{8}$ & 3 & 1 & 3 & 1 & 7 & 8 \\
\hline 18. & 24 & M & 49 & +ve & +ve & $6.9 \times 10^{10}$ & 1 & 1 & 1 & 1 & 3 & 4 \\
\hline 19. & 22 & M & 32 & $+\mathrm{ve}$ & +ve & $1 \times 10^{12}$ & 1 & 1 & 1 & 1 & 3 & 4 \\
\hline 20. & 26 & M & 31 & +ve & -ve & $2 \times 10^{4}$ & 6 & 1 & 3 & 3 & 10 & 13 \\
\hline 21. & 19 & $\mathrm{~F}$ & 28 & + ve & +ve & $4.8 \times 10^{5}$ & 3 & 1 & 3 & 3 & 7 & 10 \\
\hline 22. & 31 & M & 26 & +ve & -ve & $2 \times 10^{4}$ & 1 & 1 & 1 & 1 & 3 & 4 \\
\hline 23. & 20 & M & 29 & + ve & -ve & $1.3 \times 10^{4}$ & 3 & 1 & 1 & 3 & 5 & 8 \\
\hline 24. & 20 & M & 59 & $+\mathrm{ve}$ & + ve & $6.1 \times 10^{6}$ & 1 & 1 & 0 & 1 & 2 & 3 \\
\hline 25. & 20 & $\mathrm{~F}$ & 68 & +ve & +ve & $3.9 \times 10^{11}$ & 1 & 1 & 1 & 1 & 3 & 4 \\
\hline 26. & 23 & M & 36 & + ve & -ve & $1.74 \times 10^{5}$ & 1 & 1 & 1 & 1 & 3 & 4 \\
\hline 27. & 17 & M & 103 & +ve & -ve & $1.3 \times 10^{5}$ & 6 & 1 & 4 & 3 & 11 & 14 \\
\hline 28. & 28 & $\mathrm{~F}$ & 27 & $+\mathrm{ve}$ & +ve & $4.7 \times 10^{11}$ & 1 & 1 & 3 & 1 & 5 & 6 \\
\hline 29. & 24 & M & 62 & $+\mathrm{ve}$ & +ve & $1.2 \times 10^{9}$ & 1 & 1 & 1 & 1 & 3 & 4 \\
\hline 30. & 24 & M & 47 & + ve & +ve & $7.7 \times 10^{9}$ & 3 & 1 & 3 & 1 & 7 & 8 \\
\hline 31. & 30 & $\mathrm{M}$ & 67 & +ve & -ve & $2.4 \times 10^{3}$ & 3 & 1 & 1 & 1 & 5 & 6 \\
\hline 32. & 28 & M & 25 & +ve & -ve & $5.1 \times 10^{3}$ & 1 & 1 & 1 & 1 & 3 & 4 \\
\hline 33. & 14 & M & 44 & +ve & -ve & $1.4 \times 10^{3}$ & 1 & 1 & 1 & 1 & 3 & 4 \\
\hline 34. & 38 & $\mathrm{~F}$ & 33 & + ve & -ve & $1.3 \times 10^{3}$ & 1 & 1 & 1 & 1 & 3 & 4 \\
\hline 35. & 20 & M & 18 & +ve & -ve & $6.9 \times 10^{3}$ & 3 & 1 & 3 & 1 & 7 & 8 \\
\hline 36. & 24 & M & 47 & + ve & -ve & $1.2 \times 10^{3}$ & 3 & 1 & 3 & 1 & 7 & 8 \\
\hline 37. & 26 & M & 75 & +ve & -ve & $1.3 \times 10^{3}$ & 1 & 1 & 1 & 1 & 3 & 4 \\
\hline 38. & 30 & M & 41 & $+\mathrm{ve}$ & -ve & $6.5 \times 10^{3}$ & 3 & 1 & 3 & 3 & 7 & 10 \\
\hline 39. & 18 & M & 63 & +ve & -ve & $5.1 \times 10^{3}$ & 1 & 1 & 1 & 1 & 3 & 4 \\
\hline 40. & 24 & M & 28 & +ve & +ve & $4.9 \times 10^{8}$ & 1 & 1 & 3 & 1 & 5 & 6 \\
\hline 41. & 35 & M & 48 & +ve & -ve & $3 \times 10^{4}$ & 1 & 1 & 1 & 1 & 3 & 4 \\
\hline 42. & 27 & $\mathrm{~F}$ & 33 & +ve & -ve & $2.8 \times 10^{3}$ & 1 & 0 & 1 & 1 & 2 & 3 \\
\hline 43. & 22 & M & 66 & $+\mathrm{ve}$ & -ve & $8.4 \times 10^{4}$ & 3 & 1 & 3 & 3 & 7 & 10 \\
\hline 44. & 20 & M & 71 & +ve & +ve & $3 \times 10^{8}$ & 3 & 1 & 3 & 1 & 7 & 8 \\
\hline 45. & 28 & M & 44 & + ve & -ve & $6.7 \times 10^{4}$ & 1 & 1 & 1 & 3 & 3 & 6 \\
\hline 46. & 15 & M & 46 & +ve & + ve & $1.4 \times 10^{9}$ & 1 & 1 & 3 & 3 & 5 & 8 \\
\hline 47. & 20 & M & 43 & +ve & -ve & $8.3 \times 10^{2}$ & 1 & 1 & 3 & 1 & 5 & 6 \\
\hline 48. & 26 & M & 41 & $+\mathrm{ve}$ & -ve & $2.7 \times 10^{3}$ & 3 & 1 & 1 & 1 & 5 & 6 \\
\hline 49. & 25 & $\mathrm{~F}$ & 50 & +ve & + ve & $8.3 \times 10^{6}$ & 3 & 1 & 3 & 1 & 7 & 8 \\
\hline 50. & 23 & $\mathrm{~F}$ & 30 & +ve & -ve & $3.7 \times 10^{3}$ & 1 & 1 & 1 & 1 & 3 & 4 \\
\hline 51. & 27 & M & 42 & +ve & -ve & $6.7 \times 10^{3}$ & 3 & 1 & 1 & 3 & 5 & 8 \\
\hline 52. & 30 & M & 22 & +ve & -ve & $1 \times 10^{3}$ & 1 & 1 & 1 & 1 & 3 & 4 \\
\hline
\end{tabular}


Histopathological Assessment of Liver Biopsy Specimen in the Context of HBV DNA and HBeAg in Patients

\begin{tabular}{|c|c|c|c|c|c|c|c|c|c|c|c|c|}
\hline \multirow{2}{*}{$\begin{array}{l}\text { Case } \\
\text { no. }\end{array}$} & \multirow{2}{*}{$\begin{array}{c}\text { Age } \\
\text { (in years) }\end{array}$} & \multirow[t]{2}{*}{ Sex } & \multirow{2}{*}{$\frac{\text { Biochemical }}{\text { S. ALT (U/L) }}$} & \multicolumn{3}{|c|}{ Serological } & \multicolumn{6}{|c|}{ Histology active index } \\
\hline & & & & HBsAg & HBeAg & $\begin{array}{l}\text { HBV DNA } \\
\text { copies/ml }\end{array}$ & $P N+B N$ & $I D+F N$ & P1 & Fibrosis & HAI/18 & Knodell/22 \\
\hline 53. & 42 & $\mathrm{~F}$ & 46 & +ve & - ve & $2.1 \times 10^{3}$ & 3 & 1 & 1 & 3 & 5 & 8 \\
\hline 54. & 55 & M & 30 & + ve & +ve & $1.9 \times 10^{12}$ & 3 & 1 & 3 & 3 & 7 & 10 \\
\hline 55. & 28 & $\mathrm{M}$ & 44 & +ve & - ve & $1.1 \times 10^{7}$ & 3 & 3 & 3 & 3 & 9 & 12 \\
\hline 56. & 25 & $\mathrm{M}$ & 44 & + ve & + ve & $9 \times 10^{7}$ & 1 & 1 & 1 & 1 & 3 & 4 \\
\hline 57. & 28 & $\mathrm{M}$ & 30 & +ve & +ve & $1.1 \times 10^{4}$ & 1 & 1 & 1 & 1 & 3 & 4 \\
\hline 58. & 20 & $\mathrm{M}$ & 35 & +ve & + ve & $1.4 \times 10^{4}$ & 1 & 1 & 1 & 1 & 3 & 4 \\
\hline 59. & 22 & $\mathrm{~F}$ & 44 & +ve & +ve & $1.9 \times 10^{5}$ & 1 & 1 & 1 & 1 & 3 & 4 \\
\hline 60. & 36 & M & 91 & + ve & - ve & $1.8 \times 10^{4}$ & 3 & 3 & 4 & 3 & 10 & 13 \\
\hline 61. & 19 & $\mathrm{M}$ & 41 & +ve & +ve & $6.0 \times 10^{11}$ & 3 & 1 & 3 & 1 & 7 & 8 \\
\hline 62. & 28 & $\mathrm{M}$ & 58 & +ve & - ve & $1.5 \times 10^{5}$ & 1 & 1 & 1 & 0 & 3 & 3 \\
\hline 63. & 25 & $\mathrm{M}$ & 110 & +ve & -ve & $2.0 \times 10^{3}$ & 1 & 0 & 1 & 1 & 2 & 3 \\
\hline 64. & 42 & $\mathrm{M}$ & 70 & + ve & - ve & $5.25 \times 10^{5}$ & 3 & 1 & 1 & 1 & 5 & 86 \\
\hline 65. & 14 & $\mathrm{~F}$ & 27 & +ve & +ve & $4.1 \times 10^{9}$ & 3 & 1 & 3 & 1 & 7 & 8 \\
\hline 66. & 22 & $\mathrm{M}$ & 23 & +ve & + ve & $2.0 \times 10^{6}$ & 3 & 1 & 3 & 1 & 7 & 8 \\
\hline 67. & 16 & $\mathrm{M}$ & 48 & +ve & +ve & $4.0 \times 10^{9}$ & 1 & 0 & 1 & 0 & 2 & 2 \\
\hline 68. & 18 & $\mathrm{~F}$ & 28 & + ve & + ve & $4.5 \times 10^{11}$ & 3 & 1 & 3 & 1 & 7 & 8 \\
\hline 69. & 19 & M & 60 & +ve & + ve & $6.2 \times 10^{5}$ & 1 & 1 & 3 & 1 & 5 & 6 \\
\hline 70. & 56 & $\mathrm{M}$ & 48 & +ve & +ve & $1.1 \times 10^{10}$ & 3 & 4 & 3 & 1 & 10 & 11 \\
\hline 71. & 24 & $\mathrm{~F}$ & 48 & +ve & + ve & $2.4 \times 10^{12}$ & 3 & 1 & 3 & 1 & 7 & 8 \\
\hline 72. & 21 & M & 50 & +ve & +ve & $1.15 \times 10^{9}$ & 5 & 3 & 1 & 1 & 9 & 10 \\
\hline 73. & 25 & $\mathrm{M}$ & 110 & +ve & +ve & $1.6 \times 10^{6}$ & 1 & 1 & 1 & 1 & 5 & 6 \\
\hline 74. & 25 & $\mathrm{M}$ & 35 & +ve & -ve & $1 \times 10^{5}$ & 1 & 3 & 1 & 1 & 3 & 4 \\
\hline 75. & 23 & $\mathrm{M}$ & 57 & +ve & -ve & $1.2 \times 10^{3}$ & 1 & 1 & 1 & 1 & 3 & 4 \\
\hline 76. & 35 & $\mathrm{M}$ & 36 & +ve & - ve & $1.3 \times 10^{5}$ & 3 & 1 & 3 & 3 & 7 & 10 \\
\hline 77. & 24 & $\mathrm{M}$ & 36 & +ve & -ve & $1.88 \times 10^{5}$ & 5 & 3 & 3 & 3 & 11 & 14 \\
\hline
\end{tabular}

DNA, 13/15 had minimal to mild fibrosis (HAI-F 0-1) and 2/15 had bridging fibrosis (HAI-F 3) (Table 4).

The extents of hepatitis and hepatic fibrosis in two HBeAg-positive CHB patients and three HBeAg-negative patients were shown in Figures $1 \mathrm{~A}$ and $\mathrm{B}$ and Figures 2A to $\mathrm{C}$. It seems that liver histology was independent of the HBeAg expression or levels of ALT or HBV DNA concentrations.

\section{DISCUSSION}

The aim of this study was to assess whether HBV DNA may be used as a surrogate marker of liver damages in CHB patients of Bangladesh. Some investigators have reported about the utility of HBV DNA in assessing liver damages. ${ }^{2-8}$ Also, a role of serum HBV DNA has been shown as a marker of prognosis of antiviral therapy in CHB patients. ${ }^{15-19}$ As Bangladesh harbors about 8 to 10 million chronic HBV infected subjects, we studied if serum HBV DNA levels can be used to assess the extent of liver damages in CHB patients from Bangladesh. The present study provided mixed signals about the significance of serum HBV DNA in CHB patients. In HBeAg-positive patients, the high levels of serum HBV DNA were not related with increased levels of liver damages. This was seen in the context of both liver inflammation and hepatic fibrosis. However, in patients with HBeAg-negative CHB, some patients with high HBV DNA also had comparatively higher levels of liver damages. Taken together, it does not appear that HBV DNA or HBeAg reflect proper surrogate marker of liver damages in CHB patients of Bangladesh.

The study presented here contradicted what that have been reported by other investigators about the impact of serum HBV DNA for determining extent of liver damages in CHB patients. ${ }^{2-8}$ But, this study has apparently supported several studies about little impact of HBV DNA from developing countries. ${ }^{9-12}$

In fact, studies from Bangladesh and India along with other countries have already shown that patients with very low levels of HBV DNA also exhibit considerable levels of liver damages. Al-Mahtab et al have shown that considerable numbers of HBeAg-negative patients with $<10,000$ copies/ml of HBV DNA, and normal ALT had severe liver inflammation and hepatic fibrosis. ${ }^{20}$

However, there are several limitations of this study and the outcomes should be cautiously analyzed to develop insights about HBV pathogenesis. We have enrolled few patients in this study, which may not be enough to draw a firm conclusion. The next, we took liver biopsies for once 
only that may not be sufficient to assay the kinetics of hepatic damages of these patients. In addition, HBV DNA was measured once. In fact, this preliminary study indicates that a controlled study with considerable numbers of patients should be conducted in future.

In fact, management of CHB patients is a critical factor in developing countries including Bangladesh. ${ }^{21-23}$ Lacks of proper surrogate markers of antiviral therapy make the management of CHB patients difficult. Taken together, it appears that pathogenesis of CHB is a complex issue and dependence of HBV markers should be cautiously planned for developing insights about HBV pathogenesis and management of CHB patients.

\section{REFERENCES}

1. Ganem D, Prince AM. Hepatitis B virus infection-natural history and clinical consequences. New Eng J Med 2004;350:1118-29.

2. Fattovich G, Bortolotti F, Donato F. Natural history of chronic hepatitis B: Special emphasis on disease progression and prognostic factors. J Hepatol 2008;48:335-52.

3. Iloeje UH, Yang HI, Su J, Jen CL, You SL, Chen CJ. Predicting liver cirrhosis risk based on the level of circulating hepatitis B viral load. Gastroenterology 2006;130:678-86.

4. Chen CJ, Yang HI, Su J, et al. Risk of hepatocellular carcinoma across a biological gradient of serum hepatitis B virus DNA level. JAMA 2006;295:65-73.

5. Chen CJ, Iloeje UH, Yang HI. Serum hepatitis B virus DNA as a predictor of the development of cirrhosis and hepatocellular carcinoma. Curr Hepat Rep 2007;6:9-16.

6. Yeo W, Mo FK, Chan SL, et al. Hepatitis B viral load predicts survival of HCC patients undergoing systemic chemotherapy. Hepatology 2007;45:1382-89.

7. Feld JJ, Ayers M, El-Ashry D, Mazzulli T, Tellier R, Heathcote EJ. Hepatitis B virus DNA prediction rules for hepatitis B e antigen-negative chronic hepatitis B. Hepatology 2007;46: 1057-70.

8. Papatheodoridis GV, Manesis EK, Manolakopoulos S, et al. Is there a meaningful serum hepatitis B virus DNA cut-off level for therapeutic decisions in hepatitis B e antigen-negative chronic hepatitis B virus infection? Hepatology 2008;48:1451-59.

9. Kumar M, Sarin SK, Hissar S, et al. Virologic and histologic features of chronic hepatitis B virus-infected asymptomatic patients with persistently normal ALT. Gastroenterology 2008; 134:1376-84.
10. Kumar M, Chauhan R, Gupta N, Hissar S, Sakhuja P, Sarin SK. Spontaneous increases in alanine aminotransferase levels in asymptomatic chronic hepatitis B virus-infected patients. Gastroenterology 2009;136:1272-80.

11. El-Zayadi AR, Badran HM, Saied A, Shawky S, Attia Mel-D, Zalata K. Evaluation of liver biopsy in Egyptian HBeAg-negative chronic hepatitis B patients at initial presentation: Implications for therapy. Am J Gastroenterol 2009;104:906-11.

12. Chu CM, Liaw YF. Incidence and risk factors of progression to cirrhosis in inactive carriers of hepatitis B virus. Am J Gastroenterol 2009;104:1693-99.

13. Mahtab MA, Rahman S. Correlation between serum transaminase level and HAI score in chronic hepatitis B. Ind J Gastroenterol 2005;24:124.

14. Knodell RG, Ishak KG, Black WC, et. al. Formulation and application of a numerical scoring system for assessing histological activity in asymptomatic chronic active hepatitis. Hepatology 1981;4:431-35.

15. Ribeiro RM, Germanidis G, Powers KA, et al. Hepatitis B virus kinetics under antiviral therapy sheds light on differences in hepatitis B e antigen positive and negative infections. J Infect Dis 2010;202:1309-18.

16. Chang TT. On-treatment monitoring of HBV DNA levels: Predicting response and resistance to oral antiviral therapy at week 24 versus week 48. Hepatol Int 2009;3(Suppl 1):16-23.

17. Lok AS, McMahon BJ. AASLD Guidelines Chronic hepatitis B; Update 2009; Hepatology 2009;50:1-36.

18. European Association for the Study of the Liver. EASL clinical practice guidelines. Management of chronic hepatitis B. J Hepatol 2009;50:227-42.

19. Liaw YF, Leung N, Kao JH, et al. Asian-Pacific consensus statement on the management of chronic hepatitis B: A 2008 update. Hepatol Int 2008;22:262-83.

20. Al-Mahtab M, Rahman S, Akbar SM, Kamal M, Khan SI. Clinical use of liver biopsy for the diagnosis and management of inactive and asymptomatic hepatitis B virus carriers in Bangladesh. Journal of Medical Virology 2010;82:1350-54.

21. Akbar SM, Hiasa Y, Mishiro S, Onji M. Treatment of hepatitis $B$ virus-infected patients: Utility of therapeutic recommendations in developing countries. Expert Opin Pharmacother 2009;10: 1605-14.

22. Akbar SM, Al-Mahtab M, Hiasa Y. Future aspects of therapy for hepatitis B virus infection: Value of surrogate markers, innovative therapy, and global collaboration. J Gastroenterol (in press).

23. Liaw YF. Antiviral therapy of chronic hepatitis B: Opportunities and challenges in Asia. J Hepatol 2009;51:403-07. 